\title{
Nurses strategies to address self-care aspects related to medication adherence and symptom recognition in heart failure patients: An in- depth look
}

Tiny Jaarsma, Mariana Nikolova-Simons and Martje H L van der Wal

\section{Linköping University Post Print}

N.B.: When citing this work, cite the original article.

Original Publication:

Tiny Jaarsma, Mariana Nikolova-Simons and Martje H L van der Wal, Nurses strategies to address self-care aspects related to medication adherence and symptom recognition in heart failure patients: An in-depth look, 2012, Heart \&amp; Lung, (41), 6, 583-593.

http://dx.doi.org/10.1016/j.hrtlng.2012.03.003

Copyright: Elsevier

http://www.elsevier.com/

Postprint available at: Linköping University Electronic Press

http://urn.kb.se/resolve?urn=urn:nbn:se:liu:diva-86379 
Title:

Nurses' strategies to address self-care aspects related to medication adherence and symptom recognition in heart failure patients: an in-depth look

Authors:

Tiny Jaarsma, Department of Social and Welfare studies, Faculty of Health Sciences, Linköpings University, Sweden

Mariana Simons, Philips Research Briarcliff, US

Martje H. L. van der Wal, Department of Cardiology, University Medical Center Groningen, the Netherlands

Address for correspondence:

Tiny Jaarsma

Linköpings University

Department of Social- and Welfare Studies, ISV

60174 Norrköping, Sweden

Tel +4611363550

Email: tiny.jaarsma@liu.se

Word count revised document: 3898

Acknowledgements: We would like to thank Lissette Baltussen, Janke Warink-Riemersma, Eric H.W.T Hendriks, Cindy Verstappen, Kim van Zutphen, Anneke van Anken, Gert V.J. Cleuren, Annie M.L. Obbema for their valuable input in the heart failure nurses focus group. 
We also acknowledge Johan Muskens, Rob Udink and Wim Stut from Philips Research for their help in preparing the focus group materials and improving the paper figures. The study was funded by an unrestricted grant of Philips Research. 


\begin{abstract}
Objective: Despite an increasing body of knowledge on self-care in heart failure patients, there is still a need for effective interventions. The aim is to deepen our understanding of interventions that heart failure nurses use in clinical practices to improve patient adherence to medication and symptom monitoring.
\end{abstract}

Methods: A qualitative study with a directed content analysis was conducted using data from a purposeful selected sample of Dutch speaking heart failure nurses, who completed booklets with two cases on medication adherence and symptom recognition.

Results: Nurses regularly (re-)assess patients before they decide on an intervention. They assess basic/factual information, barriers in the patient's behavior and try to find room for improvement in patient's behavior. Interventions that heart failure nurses use to improve adherence to medication and symptom monitoring were grouped in the following themes: increasing knowledge, increasing motivation and providing the patients with practical tools. Nurses also described using technology based tools, increasing social support, alternative communication, partnership approaches and coordination of care to improve adherence to medication and symptom monitoring.

Conclusion: Despite the strong focus toward the educational strategies, nurses also reported other strategies to increase patient adherence. Nurses use several strategies to improve patient adherence that are not incorporated in guidelines. These interventions need to be evaluated for further use to improve heart failure management 


\section{Introduction}

Heart failure is a chronic disease that affects an increasing number of individuals worldwide and is associated with poor outcomes, such as a poor quality of life, early mortality and frequent readmissions [1]. Self-care is considered to be a method for improving these outcomes [2] and is recommended as a part of successful heart failure treatment [3]. Selfcare can be defined as actions aimed at maintaining life, healthy functioning, and well-being [4]. One aspect of self-care is adherence to medical treatment [2]. The World Health Organization (WHO) defines adherence as the extent to which a patient' behavior coincides with (agreed) recommendations by a healthcare provider. This term is intended to be nonjudgmental without blaming the patient. Adherence to medical treatment has been identified as a serious challenge to patients and their healthcare providers since it requires adherence to multiple self-care behaviors, e.g. medication taking, symptom monitoring, diet and fluid restriction and exercise. Non-adherence to medication is related to frequent readmissions and low survival in heart failure patients [5], [6]. More recently, non-adherence to exercise and symptom monitoring (in particular daily weighing) has been found to be associated with increased risk of HF readmission and mortality [7].

Monitoring and managing symptoms are other important aspects of self-care in heart failure patients needed to optimize outcomes and possibly prevent acute hospitalization [2].

Nurses have an increasingly prominent role in disease management intervention programs promoting self-care. These programs often provide patient education, optimized treatment and follow-up [3], [8], [9].

In addition to the implementation of evidence based interventions it is important to recognize the availability of clinical knowledge and expertise derived from expert practice [10]. By bringing both together, innovative interventions that can influence outcomes can be developed in research and then translated into clinical practice. The aim of our study was to 
deepen our understanding of the interventions heart failure nurses use in clinical practice to improve adherence to medication and symptom monitoring in heart failure patients.

\section{Method and Analysis}

The method is derived from methods using vignettes to describe decision making by nurses (for example in pain management) [11]._Qualitative data were collected from a purposeful selected sample of Dutch speaking heart failure nurses. We identified the nurses by selecting them from all HF nurses in the Netherlands. We purposefully looked for nurses who could provide rich information for an in depth study and be diverse in the number of years working in HF (many and less), education (NP and HF specialized nurse), working settings (academic and community hospital, HF clinic and homecare) and geography in the Netherlands (Table 1). Two male and six female heart failure nurses, ranging between 28 and 62 years of age were included. Both heart failure nurses with a formal Nurse Practitioner (NP) qualification and nurses specialized in heart failure, although not officially recognized as a NP, were included. In the Netherlands, NP's and specialized nurses have similar roles in heart failure care and comparable responsibility with regard to up titration of medication, patient education and self-care.

\section{$\underline{\text { Procedure }}$}

The 8 nurses were approached to share their experience of interventions they would use in practice to improve adherence to medication and symptom recognition in heart failure patients. All of the nurses completed booklets that were developed for this study and distributed in advance as a data gathering tool. In the booklets two cases of the same patient were described, addressing a number of challenges regarding adherence to medication and symptom recognition. 
The cases were developed by a HF research expert and were then checked for completeness, relevance and format by 2 experienced HF nurses and 2 independent researchers. For each case the heart failure nurses were presented with 2 tables: 'Current patient status' and 'Dilemma' (see example of the medication adherence case in Tables 2 and 3). Current patient status describes the patient's demographics, medical history, co-morbidities, medications and psycho-social status. Dilemma describes a number of challenges for the heart failure nurse bringing a patient from the "current situation" (revealing the patient's problem with adherence) to the "desired situation" (characterized by adherence to desired behavior). The challenges indicate a gradually increasing complexity of the patient case. For each challenge the nurses were asked to describe how they would address this in daily clinical practice. At the end of each case the nurses were given the opportunity to elaborate in writing on additional challenges and to describe what additional patient information they considered necessary.

\section{Medication Adherence Case}

The medication adherence case describes $\mathrm{Mr} \mathrm{B}$ who adheres to the current medication scheme. However, his medication schedule is not optimal according to the guidelines [3] and the heart failure nurse is expected to up-titrate the current $\mathrm{HF}$ medication of Mr. B to optimal doses of HF medication. (OHFM). For Mr B, an implication of the changes in medication is a new medication scheme, which may become problematic due to a change in his routine. In addition, Mr B's non-adherence to heart failure clinic visits in order to check his electrolytes and vital signs, challenges the heart failure nurse in up-titrating safely. The case therefore reveals two potential problems P1: Non-optimal HF medication and P2: Non-adherence to a new medication scheme after up-titration as indicated in Figure 3. The nurse's action that causes the potential problem P2 is depicted in the upper part of Figure 3, whilst the lower part depicts the analysis of the patient's behaviors that cause problems P1 and P2. 
Figure 1: Medication Adherence Case - problems to tackle
Who
Current
Desired Situation

\begin{tabular}{lll} 
Problems: & $\begin{array}{l}\text { Nurse's action that causes the potential problem P2: } \\
\text { 1. Changing the current medication scheme which Mr. B is adherent to; } \\
\text { adherent }\end{array}$ & $\begin{array}{l}\text { P1: Non-optimal HF medications } \\
\text { P2: Non-adherent to new meds } \\
\text { scheme after up-titration }\end{array}$ \\
\hline
\end{tabular}

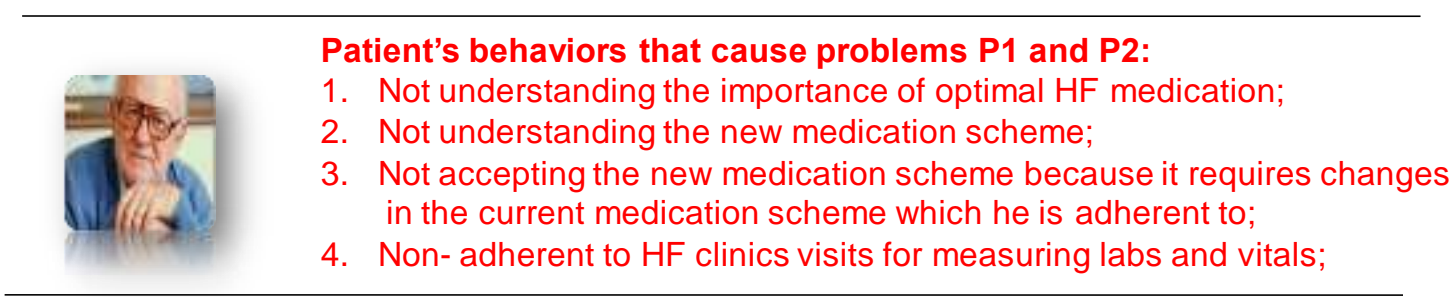

1 OHFM - Optimal Heart Failure Medication according to guidelines

Figure 2: Medication Adherence Categories

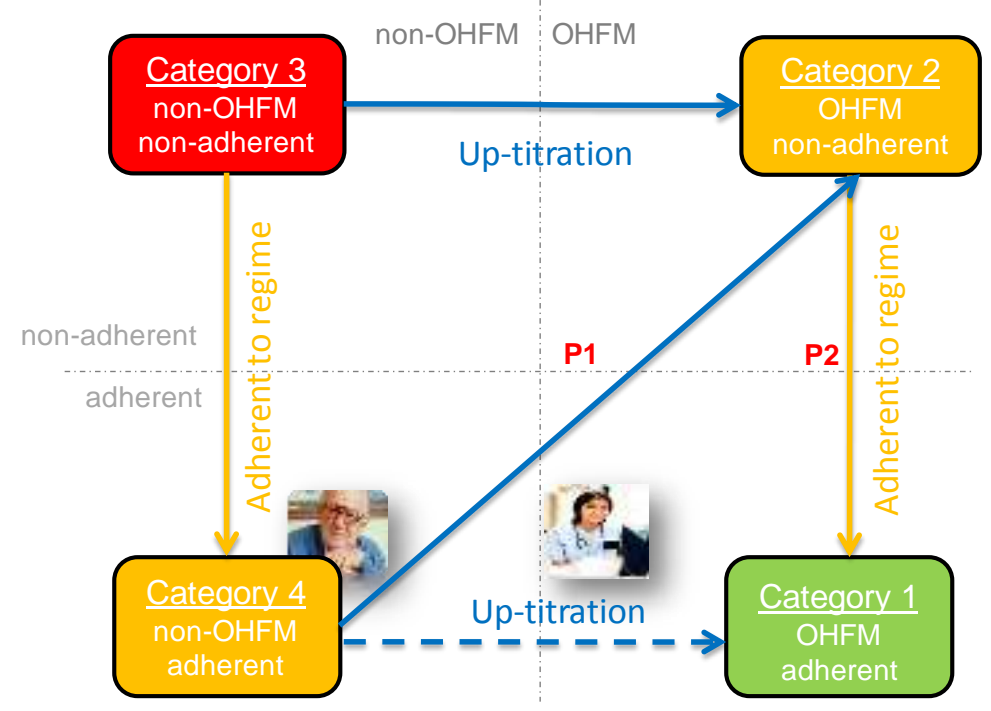


The medication adherence case has two dimensions: "X: from non-OHFM to OHFM" and "Y: from non-adherent to adherent" depicted in Figure 4. When combined, four patients categories are distinguished: Category 1 comprises: "OHFM and adherent", category 2: "OHFM and non-adherent", category 3: "non-OHFM and non-adherent" and category 4: "non-OHFM and adherent". Mr B falls into in Category 4 (adherent to medication, but not on optimal HF medication). The heart failure nurse aims to move him into Category 1 (adherent and on optimal HF medication) by safe up-titration (Figure 4). However, the patient's behaviors listed in Figure 3. might cause Mr B to go first to Category 2 (noncompliant and optimal medication) which means that the nurse will need to use a number of adherence behavior interventions to move him to Category 1.

\section{$\underline{\text { Data Analysis }}$}

The data analysis started by deriving data from the interventions described in the booklets by the heart failure nurses for each case. A directed content analysis was used [12], which is a subjective interpretation of the context of text data through a systematic classification process of coding and identifying themes or patterns. The data analysis began by reading the input in the booklets completed by the nurses, to achieve an understanding of the total descriptions and capture the essential meaning. Two coders gained in-depth knowledge of the booklets and were aware of the content of the data and what they meant, so that they were able to ascertain the relevant pieces of the material when trying to answer the research question. The booklets were read and re-read and a direct content analysis was performed in several steps. First, theoretical guidance for predetermined codes of interventions was derived from a Dutch textbook on heart failure management [13], which describes interventions to improve adherence in heart failure patients. Second, all the interventions described by the nurses were coded into a list of interventions by two independent coders using the predetermined codes. 
Disagreements on how a certain intervention should be coded were resolved based on a mutual agreement or consultancy with a third coder. Third, the list of interventions was (re)read and grouped into categories of either existing interventions or new interventions. Fourth, categories were refined and extended and existing interventions were grouped together into overarching subcategories 'assessments' and 'interventions'. Data was enriched by re-discussing the meaning of new interventions.

Trustworthiness: To address credibility, two different self-care issues instead of just one were included. Although this approach does not meet the exact definition of "triangulation" it provides a richer and more credible data set. Data was analyzed by an experienced HF nurse researcher (TJ) as well as a non- nursing researcher (MS). In case of disagreement, a competent peer (MvdW) was asked for additional input until consensus was reached. Once the results had been analyzed this peer also critically reviewed and commented on the interpretation. Finally, the results of the analysis were checked with all participants by sharing them and asking for feedback.

Saturation: Certain interventions in the categories 'assessment' and 'existing interventions' were consequently mentioned by all the nurses. All other interventions were also mentioned several times, by at least one or mostly by several nurses. All new interventions were mentioned by several nurses. 


\begin{tabular}{|c|c|c|c|c|}
\hline \multicolumn{5}{|c|}{ Heart Failure $(H F)$ nurses sample } \\
\hline Gender & \multicolumn{2}{|c|}{$\begin{array}{c}\text { Female } \\
6\end{array}$} & \multicolumn{2}{|c|}{$\begin{array}{c}\text { Male } \\
2\end{array}$} \\
\hline Age range: & \multicolumn{4}{|c|}{$28-62$ years } \\
\hline $\begin{array}{c}\text { Number of years } \\
\text { in } \mathbf{H F}\end{array}$ & \multicolumn{2}{|c|}{$\begin{array}{c}\text { Long }(>=5) \\
5\end{array}$} & \multicolumn{2}{|c|}{$\begin{array}{c}\text { Short }(<5) \\
3\end{array}$} \\
\hline Education level & \multicolumn{2}{|c|}{$\begin{array}{c}\text { Nurse Practitioner } \\
3 \\
\end{array}$} & \multicolumn{2}{|c|}{$\begin{array}{l}\text { HF Specialized nurse } \\
5\end{array}$} \\
\hline \multirow[t]{2}{*}{ Working settings } & \multicolumn{2}{|c|}{$\begin{array}{c}\text { Academic } \\
2\end{array}$} & \multicolumn{2}{|c|}{$\begin{array}{c}\text { Community } \\
6\end{array}$} \\
\hline & \multicolumn{2}{|c|}{$\begin{array}{l}\text { Heart Failure clinic } \\
7\end{array}$} & \multicolumn{2}{|c|}{$\begin{array}{c}\text { Home care } \\
1\end{array}$} \\
\hline $\begin{array}{c}\text { Geographical region } \\
\text { in the Netherlands }\end{array}$ & $\begin{array}{c}\text { North } \\
2\end{array}$ & $\begin{array}{c}\text { South } \\
2\end{array}$ & $\begin{array}{c}\text { West } \\
1\end{array}$ & $\begin{array}{c}\text { East } \\
3\end{array}$ \\
\hline
\end{tabular}

Table 2: Medication Adherence Case: Current Patient Status

\begin{tabular}{|c|c|c|}
\hline \multicolumn{3}{|c|}{ Case I: Medication Adherence - description } \\
\hline \multicolumn{3}{|c|}{ Current patient status } \\
\hline Demographics & \multicolumn{2}{|l|}{$\begin{array}{l}\text { Name: Mr. B } \\
\text { Gender: male } \\
\text { Age: } 70 \text { years old }\end{array}$} \\
\hline Medical Hx & \multicolumn{2}{|c|}{$\begin{array}{l}\text { - He has been a HF patient for } 2 \text { years now. } \\
\text { - } \quad \text { LVEF this year } 35 \% \text {. } \\
\text { - He has had an MI } 6 \text { years ago. } \\
\text { - He also suffered from a mild stroke } 2 \text { years ago. }\end{array}$} \\
\hline $\begin{array}{l}\text { Co- } \\
\text { morbidities }\end{array}$ & \multicolumn{2}{|l|}{ COPD } \\
\hline \multirow[t]{2}{*}{ Medications } & $\begin{array}{ll}\text { 1. } & \text { Nebivolol } 1 \times 5 \mathrm{mg} \\
\text { 2. } & \text { Ramipril } 2 \text { dd. } 2.5 \mathrm{mg} \\
\text { 3. } & \text { Sintrom } \\
\text { 4. } & \text { Bumetanide } 2 \mathrm{dd} .2 \mathrm{mg} \\
\text { 5. } & \text { Temazepam } 10 \mathrm{mg}\end{array}$ & $\begin{array}{ll}\text { 6. } & \text { Lactulose } \\
\text { 7. } & \text { Flixotide } 2 \text { dd. } 250 \text { microgr } \\
\text { 8. } & \text { Slow K } 2 \text { dd. } 600 \mathrm{mg} \\
\text { 9. } & \text { Pantozol } 1 \text { dd. } 40 \mathrm{mg} \\
\text { 10. } & \text { Spironolacton } 1 \text { x } 12.5 \mathrm{mg}\end{array}$ \\
\hline & \multicolumn{2}{|c|}{$\begin{array}{l}\text { From the guideline perspective, the patient is not on optimal HF medication (OHFM) yet and } \\
\text { the medication needs to be up-titrated. }\end{array}$} \\
\hline $\begin{array}{l}\text { Psycho-social } \\
\text { status }\end{array}$ & \multicolumn{2}{|c|}{$\begin{array}{l}\text { - He is living alone, his wife died } 10 \text { years ago, and his } 2 \text { daughters visit him regularly, but } \\
\text { are not involved in the daily care. } \\
\text { Mr. B does not like to be dependent of others and does not like to get help from home care } \\
\text { services, pharmacy, GP or other health care providers. } \\
\text { He does visit the HF clinic but is rather skeptical towards the HF nurses. He often misses } \\
\text { an appointment because he forgot it or does not feel motivated to spend his afternoon with } \\
\text { this beautiful weather in a stuffy place as the hospital. } \\
\text { He is very strict in his medication routine and has lined up all the pill boxes on his salon } \\
\text { table. He is not motivated to get a medications week dispenser and feels that is only } \\
\text { relevant for 'old' people. When talking to him he really seems to have it all arranged very } \\
\text { well and knows exactly what he takes and when he takes it. His wording is like: I take half } \\
\text { of the blue one...etc. }\end{array}$} \\
\hline
\end{tabular}




\begin{tabular}{|l|l|l|}
\hline \multicolumn{2}{|c|}{ Case I: Medication Compliance - description } \\
\hline Dilemma & $\begin{array}{l}\text { Please write down how you tackle } \\
\text { these challenges in practice. What } \\
\text { do you do and why? }\end{array}$ \\
\hline$\#$ & Challenges & $\begin{array}{l}\text { The HF nurse needs a lot of motivational discussions to tell to the } \\
\text { patient that his medications have to be up-titrated to achieve optimal } \\
\text { medical treatment. It does not seem important to him. }\end{array}$ \\
\hline 2 & $\begin{array}{l}\text { The HF nurse will change his routine of medication taking and needs } \\
\text { to tell the patient which one to change. There is a risk that the patient } \\
\text { totally messes up the system and only will get worse. }\end{array}$ & $\begin{array}{l}\text { During up-titrating medication, the patient needs to have blood } \\
\text { pressure taken, labs drawn on a regular basis. With the experience of } \\
\text { the non-compliance to clinic visits this is a risk. }\end{array}$ \\
\hline
\end{tabular}

Table 4: Themes derived from the nurses input

\begin{tabular}{|c|c|}
\hline Category & Themes \\
\hline \multirow[t]{3}{*}{ (Re-)Assessments } & Basic/factual information (what?) \\
\hline & Assessment of barriers in patient behavior (why?) \\
\hline & Room for improvement \\
\hline Category & Themes \\
\hline \multirow[t]{6}{*}{ Existing Interventions } & Increase factual knowledge \\
\hline & Improve knowledge application \\
\hline & Convince patients \\
\hline & Encourage patient's own responsibility for behavior change \\
\hline & Encourage the patient's autonomy to decide \\
\hline & Provide practical tools \\
\hline Category & Themes \\
\hline \multirow[t]{5}{*}{ New Interventions } & Social support \\
\hline & Alternative communication approaches \\
\hline & Technology based supportive tools \\
\hline & Healthcare provider-patient collaborative relationship \\
\hline & Care coordination \\
\hline
\end{tabular}


Table 5: Examples of heart failure nurses input from both cases

\section{Heart Failure nurses input}

\section{(Re-)Assessments}

Basic/factual information (what?)

"Evaluate all medications: does the patient need all of them, can Sintrom be replaced by Aspirin, can the dose of diuretics be decreased?"

"Need to evaluate the information the patient provides on symptoms worsening"

"When was the last readmission of this patient? How often was he readmitted with acute heart failure?"

Assessment of barriers in patient behavior (why?)

"Why does he not want to record his weight?"

"Ask in depth about the refusal of the patient to take responsibility; is it anxiety for the disease?"

"Is the patient disinterested because he is alone and nobody cares for him?"

"Is the patient forgetful because of the stroke or hypoxia? Or is it a matter of another side effect? Or is it disinterest?"

"Does the patient have insight in his disease process"

Room for improvement

"How realistic is the current intervention for this patient? Does it work?

- The weight booklet does not seem to work, what would work then?"

"Get insight into the patient's lifestyle and ask the patient what he wants. Address his need for independence and ask how he sees his own future?"

"Get medication list and adherence (to be detected via refill orders ) through the pharmacy."

\section{Existing Interventions}

Increase factual knowledge

"Explain the importance of optimal medication treatment."

"Discuss the negative consequences of not taking medications as prescribed."

"Explain how the medications work and ask the patient to repeat to check his understanding." Improve knowledge application

"Integrate medication adherence and symptoms recognition rules into the daily routines of the patient, e.g., weigh yourself always in the morning after the usual bathroom routines."

\section{Convince patients}

"Try to make clear that taking medications as prescribed can prevent a readmission."

"Try to convince him to weigh regularly - a simple way to prevent deterioration of heart failure."

"Use the patients' desire of being independent as long as possible to pursue him that being compliant with a recommended treatment plan can ensure this."

Encourage patient's own responsibility for behavior change

"Let the patient himself contribute proposals how to carry out the recommended treatment."

"Nurture the patients' own responsibility in making the lifestyle changes."

"It is the challenge to change the thoughts of the patients, it should come from inside"

Encourage the patient's autonomy to decide

"Respect patients' autonomy and give him a room for own decisions."

“What is the patients' preferred way to get help - heart failure clinic, phone consult, or not be 'bothered' at all?",

"Provide care that respects the autonomy of the patients."

Provide practical tools

"Provide the patient a medication card with doses and intake time."

"Write down the changes in the medication regimen."

"Prescribe as much as possible medications with dose 'once per day'."

"Write down the weight on your calendar, no a separate booklet needed."

\section{New Interventions}

Social support 


\begin{tabular}{|c|}
\hline $\begin{array}{l}\text { "Engage relatives (e.g. a daughter), or friends (e.g. a neighbor) as caregivers to provide social support." } \\
\text { Alternative communication approaches }\end{array}$ \\
\hline $\begin{array}{l}\text { "Adapt the language and the examples to the specific patient" } \\
\text { "Use motivational interviewing to get the message across." }\end{array}$ \\
\hline Technology based supportive tools \\
\hline $\begin{array}{l}\text { "Telehealth can provide a solution to being compliant with regular measurement of weight, blood pressure and } \\
\text { pulse that are automatically sent to medical professionals." } \\
\text { "In addition to vital signs measurement the telehealth systems can collect answers from surveys related to } \\
\text { symptoms worsening and correlate them to vitals in order to detect early worsening of heart failure" }\end{array}$ \\
\hline Healthcare provider-patient collaborative relationship \\
\hline $\begin{array}{l}\text { "Work together with the patient, e.g., include the patient in making a specific treatment plan." } \\
\text { "Build up a trust relationship with the patient." }\end{array}$ \\
\hline Care Coordination \\
\hline $\begin{array}{l}\text { "Combine the different caregiver's services, e.g., blood pressure measurements by the GP or home healthcare } \\
\text { agency." } \\
\text { "Refer to cardiac rehabilitation." }\end{array}$ \\
\hline
\end{tabular}

\section{Results}

Major results were grouped into a re-assessment category, which mainly addressed the information nurses needed to determine their intervention, a category of existing interventions and finally a category of new interventions. In each category a number of themes was derived, listed in Table 4. Examples of nurses' input for each theme are displayed in Table 5.

\section{(Re-) assessment}

By grouping additional information that the nurses needed, the following themes emerged: 'basic/factual information (what?)', 'assessment of barriers in patient behavior (why?) and 'room for improvement'.

\section{$\underline{\text { Basic/factual information (what?) }}$}

In both cases the nurses wanted to know what had happened to the patient recently, e.g. the most recent readmission or how frequently the patient was readmitted.

With regard to medication adherence and challenges in up-titration, the nurses stated that they needed more information on the medication regimen, for example the reason why a specific 
medication was not prescribed to the patient (drug intolerance, side effects). In addition, they questioned whether all medications were still needed, for example certain diuretics or medication for co-morbidity such as diabetes or renal failure.

With regard to adherence to symptom recognition (daily weighing) the nurses stated that they needed more specific information on the patient's symptoms before they could plan an intervention to improve the patient's ability to recognize these symptoms, such as severity of symptoms.

\section{Assessment of barriers in patient behavior (why?)}

In the booklets, the nurses reported that they needed to gather information on the underlying reasons for the patients' current behavior particularly why a desired behavior was not performed. Several text fragments reported on the need to evaluate the reasons from the patient perspective. The nurses reported that they needed to scrutinize why mr B was not motivated to weigh himself, what prevented him from taking his medication, what kept him from recognizing symptoms? Several nurses also described their own interpretation of the underlying barriers to a desired behavior based on their own experience and expectation, for example 'forgetfulness due to stroke'.

\section{$\underline{\text { Room for improvement }}$}

Several nurses expressed the need to explore if there was 'room for improvement' in the patients' behavior and in their interventions. Their input suggested there was a need to evaluate the current intervention and to discover patient's interests and underlying motivators for a behavior change. This search for the patients' personal strengths and motivations can help to decide on an effective intervention, e.g. what does the patient like to do, what motivates him to stay healthy? Nurses also suggested using alternative information sources that might improve interventions, such as gathering information on refills of medication from the pharmacy instead of only from self-report. 


\section{Existing Interventions}

Increase factual knowledge

All nurses reported that increasing patients' knowledge was important for improving adherence to both medication and symptom recognition. They found that it was important to focus on factual knowledge and teaching the patient to apply the knowledge. The approaches were worded as: provide knowledge, give facts, tell the patient, explain, illustrate, discuss. Once the nurses' input was coded into a list of interventions, it became evident that all 8 nurses addressed the predetermined interventions related to factual knowledge.

$\underline{\text { Improve knowledge application }}$

Nurses also reported on the importance of applying knowledge in a patients' daily life and to integrate behavior in daily routines. Regarding daily weighing in particular, nurses stressed the need to discuss with patients what fits their daily routine best, for example always weighing in the morning after the usual bathroom routines or in the evening before going to bed.

\section{Convincing patients}

In addition to the transfer of knowledge, several nurses suggested 'to convince patients' to take their medication as prescribed and to weigh themselves daily. This entailed more than simply 'telling the patient' or 'informing about' possible consequences, and was formulated more as 'winning the patient over'. Some nurses formulated that 'convincing a patient' would serve as the patient's motivation to perform a certain behavior.

\section{Encourage patient's own responsibility for behavior change}

Nurses also mentioned the opportunity to make the patients responsible for the changes they need to make. In this way patients will weigh themselves not because the nurse finds it 
important ('he does not need to do it for me'), but because patients want to do it to change their outcomes.

Encourage the patient's autonomy to decide

Respecting the patient's autonomy with regard to deciding upon lifestyle change was perceived by the nurses as a way to motivate the patient. If the patient has some leeway in deciding when to perform certain self-care behavior or maybe even to decide not to adhere to a certain treatment, it might help to discuss which aspects of self-care are vital and feasible for this patient.

\section{$\underline{\text { Provide practical tools }}$}

In this case, several interventions were related to providing patients with practical tools. For example, providing the patient with a medication box, medication dosing schedules or instructing the patient where to buy a scale. Several nurses had access to a broad network of affiliated healthcare providers (e.g. pharmacist, diabetes nurse) and volunteer networks that could offer practical solutions for barriers such as medication refill, reimbursement for diets, transportation.

\section{New interventions}

Interventions mentioned by the nurses that were not included in the textbook [13] as specific intervention to increase patient adherence, were identified as new interventions.

\section{$\underline{\text { Social support }}$}

The heart failure nurses proposed to involve relatives and friends in the patients' daily care, e.g. a daughter or a neighbor who could accompany the patient to the heart failure clinic, or a spouse who could help with symptom recognition and contact healthcare providers in time.

\section{$\underline{\text { Alternative communication approaches }}$}


The nurses proposed alternative communication approaches that have shown to be effective for changing patient behavior such as tailoring the health information to the patient and using a motivational interviewing technique. The nurses elaborated specifically on tailoring health information, which includes both tailored assessments and messages. The latter refers not only to adapting language to the patients' level of understanding but also the use of examples that are close to the patients' reality (e.g. how to explain congestion). The former refers to an assessment of specific determinants of behavior, e.g. 'Is the patient forgetful due to the stroke or hypoxia? Or is it a matter of another side effect? Or is it disinterest?' (Table 5)

\section{$\underline{\text { Technology based supportive tools }}$}

One of the technology based supportive tools mentioned by several of the nurses in both cases is telehealth, in particular using a telehealth system to improve adherence to daily weighing and blood pressure control. A few nurses were familiar with different systems for monitoring bloodpressure, weight and symptoms, but these were only used in a limited number of patients.

\section{$\underline{\text { Healthcare provider-patient collaborative relationship }}$}

Nurses specifically mentioned the importance of collaborating with the patient towards mutual goals. This was proposed to be achieved by 'making a specific plan', 'building a relationship of trust with the patient' and 'working together'. In their daily care, this was not seen as routine but mentioned as something that was needed to overcome recurring adherence problems.

\section{Care Coordination}

The coordination of care by healthcare providers (primary care provider, general practitioner, home healthcare, heart failure clinic) involved in management of heart failure patients was highlighted as an important element of minimizing patients' burden and improving patients' treatment adherence. 


\section{Discussion}

This qualitative study aimed to obtain a deeper understanding of the interventions nurses use to improve adherence to medication and symptom recognition in chronic heart failure patients.

An important finding was that the primary focus of nurses' interventions was to increase patients' knowledge. Instructions, patient education, explaining and providing facts are still the most important interventions for increasing patient adherence. In the booklets, all nurses consistently mentioned the importance of focusing on knowledge. However, current theories and study findings advocate that 'telling' patients what medications they are prescribed (knowledge by recalling) is insufficient for improving patients' adherence [14], [15]. Knowledge represents the lowest level (out of 6) of learning outcomes in Bloom's taxonomy in the cognitive domain and according to previous research based on the situation-specific theory of heart failure self-care, patients need skills at the higher levels of this taxonomy [16], [17]. There seems to be a gap between the nurses' current focus (increasing knowledge) and theoretical insights of the importance of increasing self-care. For example, self-care maintenance requires active symptom monitoring. Patients need to understand and interpret the symptoms (skills at level 2 of Bloom's taxonomy). Further, patients need to recognize symptoms and signs, e.g. increased weight, and then evaluate the symptoms, e.g. detect a change in weight compared to the day before. Therefore, patients need both tactical skills (how to?, levels 3-4 of Bloom's taxonomy) and situational skills (what to do in case of a sudden weight gain during my holiday?, levels 5-6 of Bloom's taxonomy). Patients need to have skills in addition to basic knowledge that is transferred by 'telling', 'instructing' or 'providing facts'. Nurses need to be aware of the importance of perceptions of self-care and 
of the effectiveness of the interventions they utilize or that are tested, including evidence based interventions regarding self-management and self-efficacy.

The strong emphasis on patient education activities in the interventions to improve adherence was also reported in a recently published meta-analysis, describing interventions to improve medication adherence in older adults [18]. They concluded that although teaching patients about their medications and disease is important, more emphasis should be placed on behavioral strategies to increase medication adherence. Patient education should involve less verbal instructions, and individuals should be provided clear brief written instructions that they can refer to at home. Only 'telling patients what to do' might even be contra productive and such instructions are reported as unsupportive by patients themselves [19].

Since it is generally recognized that increasing knowledge is not enough to improve patient adherence, new interventions strategies should be explored. In this respect, our study extends prior findings [20] by demonstrating that despite the strong focus toward the educational strategies, nurses also reported other strategies to increase patient adherence. For example, the nurses recognized the importance to build a collaborative relationship with the patient and to tailor the health information to the patient or use motivational interviewing techniques. Patient education has proven to have impact on adherence, however it should be consistent over time, and adapted to individual patient characteristics including cognitive, educational, developmental and intellectual capabilities. In addition, the nurses proposed interventions related to social support, use of technology and care coordination. In general, little emphasis was placed on behavioral strategies for patient skills building.

Another important finding was that in addition to access to basic patient data, nurses need (re-)assessments of both 1) physiological parameters, e.g., vital signs and symptoms, and 2) behavioral parameters, e.g., motivation, barriers for adherence and self-care behavior. This is an important observation, since in a time of increasing need for clinical efficiency in patient 
care, clinical pathways might predominantly focus on efficiency and quick turnover and not always provide room for re-assessment. Furthermore, the time nurses have with patients is limited and the list of discussion topics needs to be prioritized. The (re-)assessment results can be very valuable in making this prioritization and tailoring the health information.

In contrast to a single point of measurement, re-assessments of both physiological and behavioral parameters allow the HF nurse to detect a trend that can predict an upcoming adverse event. The frequency of re-assessments necessary to generate a trend depends on the patients' characteristics, e.g., daily vs. weekly weight monitoring for unstable vs. stable patients, respectively. It is essential to re-assess behavioral parameters such as adherence to medications, or depressive symptoms, since they might not be stable over time and are related to outcomes [21].

The need for (re-)assessment of physiological and behavioral parameters might be supported by technology based tools. In this study some of the nurses suggested using a telemonitoring system to gather data on weight, blood pressure and heart rate. Although the effectiveness for improving mortally and readmission of telemonitoring in heart failure patients with the current equipment is currently under debate [22], [23], home monitoring might be valuable for individual patients.

Furthermore, technology based tools seem promising in the search for new interventions that might help to increase patient adherence. For example there are web-based information portals (e.g., heartfailurematters.org) and new generation telehealth systems [24] that are designed to simplify information, to increase patients' ability to understand and remember medical information provided during HF clinic visits, and to support the patients' behavioral change process. In addition to monitoring signs and symptoms, home based coaching programs might be used to elaborate on support for patient self-care [25], [26], [27]. Ideally, these systems will empower patients to make decisions in response to their own physiological 
and psychological information, offering the most direct path to action in connecting the circle from home to disease management [28].

This study was limited by a purposeful sample of nurses willing to discuss their views on improving patients' adherence. Although the sample was small, which is typical for qualitative investigations, the nurses do represent a diverse group with respect to number of years in heart failure, education level, work settings and geographical region. Both nurses with a formal NP training and nurses with a specialized heart failure education were included. At the time of the study in the Netherlands, these nurses generally had the same roles and responsibilities in the heart failure care. This might differ in other countries and should be recognized when generalizing results.

\section{Conclusion}

Despite the strong focus toward the educational strategies, nurses also reported other strategies to increase patient adherence. Nurses in clinical practice use several strategies to improve patient adherence that are not incorporated yet in evidence based advice. These interventions need to be evaluated for further use to improve heart failure management.

\section{Clinical Implications}

Increasing patient adherence is an important but challenging part of heart failure self-care management. Increasing patients' actual knowledge by explaining and providing facts about the goal and expected effect of the advice on behavior is a first line intervention, but often not enough. Nurses need to be aware of other approaches to motivate patients.

Continuous assessment is needed to increase behavioral changes in heart failure patients. This implies that time should be dedicated to regular assessment of patient knowledge and motivation for behavioral change. A single assessment during a first session at the heart 
failure clinic is not enough, since nurses base their interventions on changes in patients' physiological and psychological parameters. By assessing patients' personal situation, room for improvement can be found and interventions can be tailored to the individual patient.

\section{Research Implications}

There is a need to develop and test interventions that increase the application and evaluation of patient knowledge and go beyond the basic knowledge that is only used to remember, explain and describe specific behavior. 


\section{References}

1. Lloyd-Jones, D., R.J. Adams, T.M. Brown, M. Carnethon, S. Dai, G. De Simone, T.B. Ferguson, E. Ford, K. Furie, C. Gillespie, A. Go, K. Greenlund, N. Haase, S. Hailpern, P.M. Ho, V. Howard, B. Kissela, S. Kittner, D. Lackland, L. Lisabeth, A. Marelli, M.M. McDermott, J. Meigs, D. Mozaffarian, M. Mussolino, G. Nichol, V.L. Roger, W. Rosamond, R. Sacco, P. Sorlie, T. Thom, S. Wasserthiel-Smoller, N.D. Wong, and J. Wylie-Rosett, Heart disease and stroke statistics--2010 update: a report from the American Heart Association. Circulation, 2010. 121(7): p. e46-e215.

2. $\quad$ Riegel, B., D.K. Moser, S.D. Anker, L.J. Appel, S.B. Dunbar, K.L. Grady, M.Z. Gurvitz, E.P. Havranek, C.S. Lee, J. Lindenfeld, P.N. Peterson, S.J. Pressler, D.D. Schocken, and D.J. Whellan, State of the science: promoting self-care in persons with heart failure: a scientific statement from the American Heart Association. Circulation, 2009. 120(12): p. 1141-63.

3. Dickstein, K., A. Cohen-Solal, G. Filippatos, J.J. McMurray, P. Ponikowski, P.A. Poole-Wilson, A. Stromberg, D.J. van Veldhuisen, D. Atar, A.W. Hoes, A. Keren, A. Mebazaa, M. Nieminen, S.G. Priori, and K. Swedberg, ESC guidelines for the diagnosis and treatment of acute and chronic heart failure 2008: the Task Force for the diagnosis and treatment of acute and chronic heart failure 2008 of the European Society of Cardiology. Developed in collaboration with the Heart Failure Association of the ESC (HFA) and endorsed by the European Society of Intensive Care Medicine (ESICM). Eur J Heart Fail, 2008. 10(10): p. 933-89.

4. Riegel, B., B. Carlson, D.K. Moser, M. Sebern, F.D. Hicks, and V. Roland, Psychometric testing of the self-care of heart failure index. J Card Fail, 2004. 10(4): p. 350-60.

5. Wu, J.R., D.K. Moser, M.L. Chung, and T.A. Lennie, Objectively measured, but not self-reported, medication adherence independently predicts event-free survival in patients with heart failure. J Card Fail, 2008. 14(3): p. 203-10.

6. Granger, B.B., K. Swedberg, I. Ekman, C.B. Granger, B. Olofsson, J.J. McMurray, S. Yusuf, E.L. Michelson, and M.A. Pfeffer, Adherence to candesartan and placebo and outcomes in chronic heart failure in the CHARM programme: double-blind, randomised, controlled clinical trial. Lancet, 2005. 366(9502): p. 2005-11.

7. van der Wal, M.H., D.J. van Veldhuisen, N.J. Veeger, F.H. Rutten, and T. Jaarsma, Compliance with non-pharmacological recommendations and outcome in heart failure patients. Eur Heart J, 2010. 31(12): p. 1486-93.

8. Powell, L.H., J.E. Calvin, Jr., D. Richardson, I. Janssen, C.F. Mendes de Leon, K.J. Flynn, K.L. Grady, C.S. Rucker-Whitaker, C. Eaton, and E. Avery, Self-management counseling in patients with heart failure: the heart failure adherence and retention randomized behavioral trial. J Amer Med Assoc, 2010. 304(12): p. 1331-8.

9. $\quad$ Fredericks, S., H. Beanlands, K. Spalding, and M. Da Silva, Effects of the characteristics of teaching on the outcomes of heart failure patient education interventions: a systematic review. Eur J Cardiovasc Nurs, 2010. 9(1): p. 30-7.

10. Day, L., Evidence-based practice, rule-following, and nursing expertise. Am J Crit Care, 2009. 18(5): p. 479-82.

11. Hamers, J.P., M.A. van den Hout, R.J. Halfens, H.H. Abu-Saad, and A.E. Heijltjes, Differences in pain assessment and decisions regarding the administration of analgesics between novices, intermediates and experts in pediatric nursing. Int J Nurs Stud, 1997. 34(5): p. 325-34.

12. Hsieh, H.F. and S.E. Shannon, Three approaches to qualitative content analysis. Qual Health Res, 2005. 15(9): p. 1277-88. 
13. Jaarsma, T. and v.D. Veldhuisen, eds. Zorg en hartfalen (Heart failure care). [in Dutch] BSL ISBN 903133769 2. 2004, Houten.

14. Nieuwenhuis, M.M., M.H. van der Wal, and T. Jaarsma, The Body of Knowledge on Compliance in Heart Failure Patients: We Are Not There Yet. J Cardiovasc Nurs, 2010.

15. Clark, A.M., C.N. Freydberg, F.A. McAlister, R.T. Tsuyuki, P.W. Armstrong, and L.A. Strain, Patient and informal caregivers' knowledge of heart failure: necessary but insufficient for effective self-care. Eur J Heart Fail, 2009. 11(6): p. 617-21.

16. Riegel, B. and V.V. Dickson, A situation-specific theory of heart failure self-care. J Cardiovasc Nurs, 2008. 23(3): p. 190-6.

17. Jaarsma, T., A. Stromberg, J. Martensson, and K. Dracup, Development and testing of the European Heart Failure Self-Care Behaviour Scale. Eur J Heart Fail, 2003. 5(3): p. 363-70.

18. Conn, V.S., A.R. Hafdahl, P.S. Cooper, T.M. Ruppar, D.R. Mehr, and C.L. Russell, Interventions to improve medication adherence among older adults: meta-analysis of adherence outcomes among randomized controlled trials. Gerontologist, 2009. 49(4): p. 447-62.

19. Riegel, B. and B. Carlson, Facilitators and barriers to heart failure self-care. Patient Educ Couns, 2002. 46(4): p. 287-95.

20. Berben, L., L. Bogert, M.E. Leventhal, B. Fridlund, T. Jaarsma, T.M. Norekval, K. Smith, A. Stromberg, D.R. Thompson, and S. De Geest, Which interventions are used by health care professionals to enhance medication adherence in cardiovascular patients? A survey of current clinical practice. Eur J Cardiovasc Nurs, 2011. 10(1): p. 14-21.

21. Lesman-Leegte, I., D.J. van Veldhuisen, H.L. Hillege, D. Moser, R. Sanderman, and T. Jaarsma, Depressive symptoms and outcomes in patients with heart failure: data from the COACH study. Eur J Heart Fail, 2009. 11(12): p. 1202-7.

22. Chaudhry, S.I., J.A. Mattera, J.P. Curtis, J.A. Spertus, J. Herrin, Z. Lin, C.O. Phillips, B.V. Hodshon, L.S. Cooper, and H.M. Krumholz, Telemonitoring in patients with heart failure. N Engl J Med, 2010. 363(24): p. 2301-9.

23. Inglis, S.C., R.A. Clark, F.A. McAlister, J. Ball, C. Lewinter, D. Cullington, S. Stewart, and J.G. Cleland, Structured telephone support or telemonitoring programmes for patients with chronic heart failure. Cochrane Database Syst Rev, 2010(8): p. CD007228.

24. Cleland, J.G., C. Lewinter, and K.M. Goode, Telemonitoring for heart failure: the only feasible option for good universal care? Eur J Heart Fail, 2009. 11(3): p. 227-8.

25. Lainscak, M., L. Blue, A.L. Clark, U. Dahlstrom, K. Dickstein, I. Ekman, T. McDonagh, J.J. McMurray, M. Ryder, S. Stewart, A. Stromberg, and T. Jaarsma, Selfcare management of heart failure: practical recommendations from the Patient Care Committee of the Heart Failure Association of the European Society of Cardiology. Eur J Heart Fail, 2011. 13(2): p. 115-26.

26. Dilles, A., V. Heymans, S. Martin, W. Droogne, K. Denhaerynck, and S. De Geest, Comparison of a computer assisted learning program to standard education tools in hospitalized heart failure patients. Eur J Cardiovasc Nurs, 2010.

27. Smeulders, E.S., J.C. van Haastregt, T. Ambergen, H.E. Stoffers, J.J. Janssen-Boyne, N.H. Uszko-Lencer, A.P. Gorgels, C.L. Lodewijks-van der Bolt, J.T. van Eijk, and G.I. Kempen, Heart failure patients with a lower educational level and better cognitive status benefit most from a self-management group programme. Patient Educ Couns, 2010. 81(2): p. 214-21. 
28. Desai, A.S. and L.W. Stevenson, Connecting the circle from home to heart-failure disease management. N Engl J Med, 2010. 363(24): p. 2364-7. 


\section{Figure legends}

Figure 3: Medication Adherence Case - problems to tackle

Figure 4: Medication Adherence Categories 
